\title{
Connecting Subseasonal Movements of the Winter Mean Ridge in Western North America to Inversion Climatology in Cache Valley, Utah
}

\author{
SHIH-Yu WANG AND RobeRT R. GILLIES \\ Utah Climate Center, and Department of Plants, Soil, and Climate, Utah State University, Logan, Utah \\ RANDY MARTIN \\ Utah Climate Center, and Department of Civil and Environmental Engineering, Utah State University, Logan, Utah
}

\author{
ROBERT E. DAVIES AND MARTY R. BOOTH \\ Utah Climate Center, Utah State University, Logan, Utah
}

(Manuscript received 9 May 2011, in final form 9 November 2011)

\begin{abstract}
A 10-yr record of $\mathrm{PM}_{2.5}$ (particulate matter of aerodynamic diameter $\leq 2.5 \mu \mathrm{m}$ ), collected in Cache Valley near downtown Logan, Utah, reveals a strong peak in the $\mathrm{PM}_{2.5}$ concentration climatology that is tightly localized in mid-January. The cause of this subseasonal variation in the $\mathrm{PM}_{2.5}$ climatology is investigated through dynamical downscaling and large-scale diagnostics. Climatological analysis of the U.S. winter mean ridge reveals a mid-January subseasonal shift in the zonal direction, likely in response to variations in the Rossby wave source over the central North Pacific Ocean. This displacement of the winter mean ridge, in turn, has an impact on regional-scale atmospheric conditions-specifically, subsidence with local leeside enhancements and midlevel warming over Cache Valley. The analyses of this study indicate that the subseasonal peak of long-term mean $\mathrm{PM}_{2.5}$ concentrations in Cache Valley is linked to the large-scale circulations' subseasonal evolution, which involves remote forcing in the circumpolar circulations as well as possible tropicalmidlatitude interactions. This subseasonal evolution of the winter mean circulation also affects precipitation along the West Coast.
\end{abstract}

\section{Introduction}

Episodes of high-concentration particulate matter $(\mathrm{PM})$, the result of prolonged wintertime inversion events and an abundance of photochemically active precursor compounds, have become common in certain valley locations in the U.S. Intermountain West (IMW). Cache Valley, Utah, is one such location that suffers from atypically high PM concentrations relative to other valleys in the IMW. Situated on the Utah-Idaho border, in the topographic transition between the basin terrain of the Great Basin and the mountainous terrain of the Rocky Mountains, Cache Valley is bounded on the west, south, and east sides by mountains and by hills on the north (Fig. 1).

Corresponding author address: Simon Wang, 4825 Old Main Hill, Logan, UT 84322.

E-mail: simon.wang@usu.edu
Elevated levels of $\mathrm{PM}_{2.5}$ (particulate matter of aerodynamic diameter $\leq 2.5 \mu \mathrm{m}$ ) in Cache Valley are primarily a wintertime phenomenon due to a combination of factors: topography, abundant precursor sources, and optimal photochemical conditions. The bulk of the area's $\mathrm{PM}_{2.5}$ consists of ammonium nitrate, whose formation is thermodynamically favored at low temperatures and high humidities (Martin 2006). The area's farming industry, combined with the concentration of mobile (automotive) sources in cities, provides a ready supply of the prime precursor species: ammonia and oxides of nitrogen. For the years 2001-10, the National Ambient Air Quality Standard (NAAQS) for $\mathrm{PM}_{2.5}$ of $35 \mu \mathrm{g} \mathrm{m}^{-3}$ (98th percentile, averaged over $3 \mathrm{yr}$ ), was exceeded on an average of approximately $20 \pm 9$ days (i.e., $95 \%$ confidence interval) each winter season. In December 2009 the U.S. Environmental Protection Agency (EPA) declared the two-state Cache Valley region a nonattainment area for $\mathrm{PM}_{2.5}$ for exceeding the 24-h 


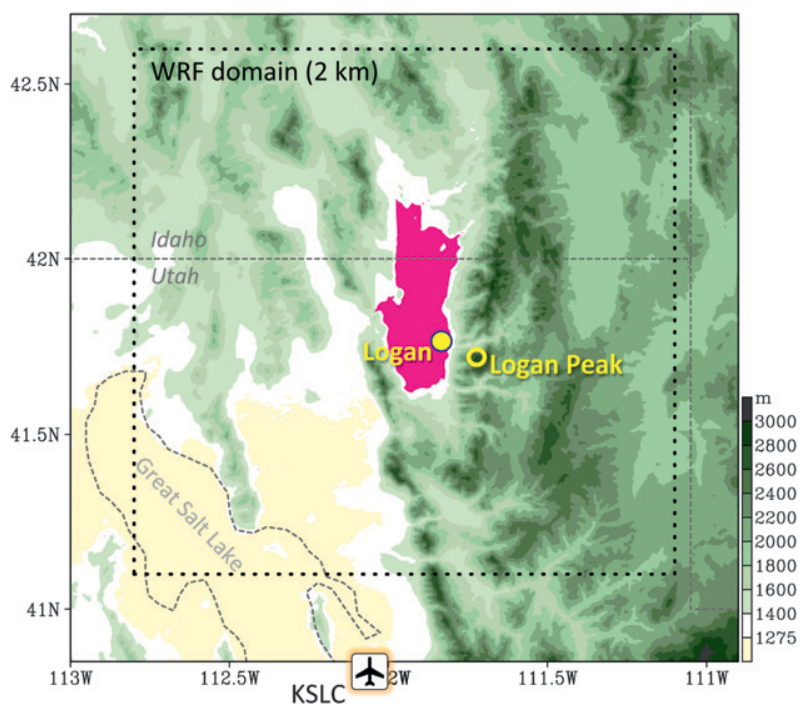

FIG. 1. Topography and locations of Cache Valley (pink area for elevations lower than $1350 \mathrm{~m}$ ) and Salt Lake City International Airport (KSLC; bottom of the map). The city of Logan is indicated by the yellow dot while Logan Peak is indicated by the yellow open circle. The simulation domain of the $2-\mathrm{km}$ WRF is outlined by dotted lines.

NAAQS. This study traces the path of a strong subseasonal signal in the local climatology of Cache Valley back to a subseasonal signal in the overlying large-scale atmospheric circulation.

This study begins with a 10 -yr record of 24-h $\mathrm{PM}_{2.5}$ collected in Cache Valley near downtown Logan, Utah, during the period 2001-10 (Malek et al. 2006; Martin 2006). Examination of this long-term record reveals a strong peak in the $\mathrm{PM}_{2.5}$ concentration climatology, tightly localized in mid-January (Fig. 2a). [The individual-year records of Cache Valley PM2.5 are available online at http://cliserv.jql.usu.edu/data/Cache_Valley_PM_year.pdf (source: Utah Division of Air Quality).] It is known that $\mathrm{PM}_{2.5}$ episodes in Cache Valley exhibit a strong seasonal dependence that maximizes in winter when cold-air pooling and the formation of strong valley inversions are most likely (Silva et al. 2007). However, the apparent subseasonal variation in the $\mathrm{PM}_{2.5}$ climatology-and hence the inversion climatology-is rather unexpected. Certainly winter snow cover enhances temperature inversions by increasing the surface albedo, subsequently elevating the $\mathrm{PM}_{2.5}$ concentrations. Still, such a surface process does not explain the repeated and highly localized timing (i.e., the subseasonal variability; Fig. 2a).

Along with other IMW valleys, Cache Valley undergoes climatologically persistent wintertime subsidence and relatively warm air in the upper troposphere caused by the semipermanent winter ridge to its west. As a result, the formation of valley cold pools (and subsequent

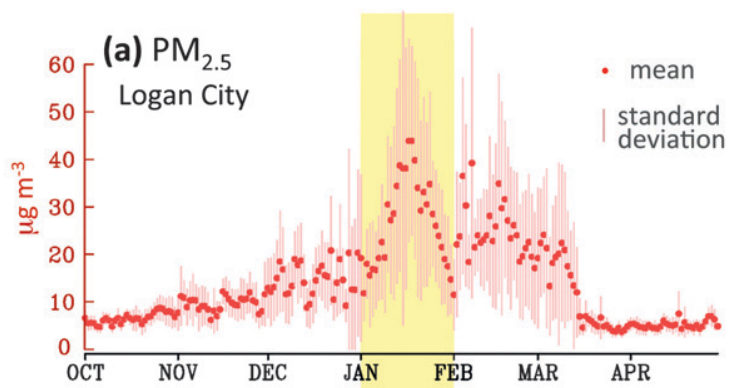

(b) (Valley inversions)
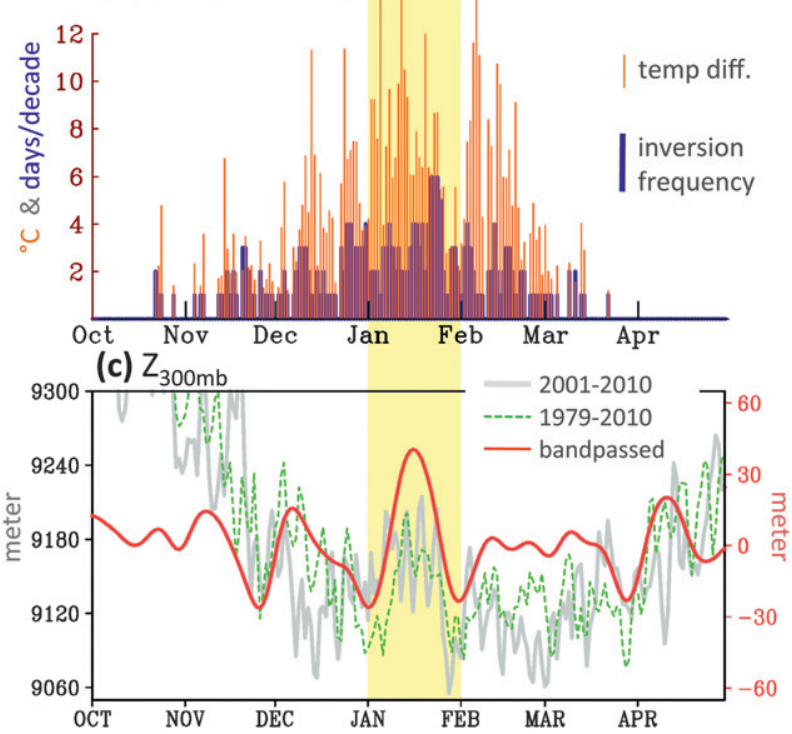

FIG. 2. (a) Daily (24-h) PM2.5 concentrations collected in Logan City, averaged over the 2001-10 period. Mean values are indicated by red dots; the standard deviation is indicated by pink bars. (b) Climatological mean temperature differences (orange bars) and the valley inversion frequency (blue bars) estimated from the two stations in Logan City and Logan Peak (see text). (c) Long-term geopotential height at $300 \mathrm{mb}$ observed at KSLC for the periods 2001-10 (gray) and 1979-2010 (green dashed); the red line is the 20-40-day bandpass filtered geopotential height for the 1979-2010 period.

elevated $\mathrm{PM}_{2.5}$ levels) is profoundly influenced by fluctuations in the winter ridge (Wolyn and McKee 1989; Whiteman 2000; Reeves and Stensrud 2009; Beaver et al. 2010), including its subseasonal variation (Gillies et al. 2010a). Previous studies have found a pronounced subseasonal oscillation (20-40 days) in the midlatitude circulations that may be linked to free Rossby waves (Lau and Nath 1999) and/or tropical intraseasonal modes such as the Madden-Julian oscillation (MJO; Mo 1999; Higgins et al. 2000). On the basis of this linkage, Gillies et al. (2010b) examined hindcasts of a climate forecast model and found that successful predictions of the winter ridge's subseasonal variation effectively extend the forecasts of prolonged inversion events and elevated $\mathrm{PM}_{2.5}$ 
levels. From these findings, the pronounced midJanuary peak of $\mathrm{PM}_{2.5}$ concentrations in Cache Valley may signify a "climatological subseasonality" in the winter circulations, a previously undocumented feature examined herein.

Our course has been to analyze the meteorological conditions associated with the $\mathrm{PM}_{2.5}$ climatology in Cache Valley and then connect these local conditions to variations in the larger-scale circulation. Because of the lack of upper-air sounding facility in Cache Valley, we employed dynamical downscaling (i.e., mesoscale modeling) to reconstruct local meteorological conditions. To quantify the reliability of this modeling approach, we scrutinized stations at different elevations to construct vertical soundings, as well as stations throughout the valley to construct circulation profiles, and compared the results to the model-generated reconstructions. In this manner we were able to evaluate the efficacy of the dynamic downscaling and use it to mediate between local conditions and the large-scale circulation. The dynamic downscaling and assessment are described in section 2; results of the local and large-scale atmospheric environments are discussed in section 3 ; and summary comments and conclusions are given in section 4 .

\section{Data sources and the model}

To obtain an observationally based approximation of vertical temperature profiles in Cache Valley, we utilized two stations at different elevations: a station on the valley floor in Logan City (1602 m above mean sea level), and a station atop Logan Peak $(2960 \mathrm{~m})$ located $6 \mathrm{mi}$ $(9.66 \mathrm{~km}$ ) east-southeast of Logan City (see Fig. 1). Both stations are on 10-m towers equipped with HMP45C Vaisala temperature and relative humidity probes and logged a complete record during the period 2001-10. The combination of these observations, then, provides a climatology composed of temperature "soundings" in Cache Valley that can be compared with the $\mathrm{PM}_{2.5}$ observations. Valley inversions were defined as the occurrences when the mean daily Logan Peak temperature $\left(\bar{T}_{P}\right)$ exceeded the mean daily valley temperature $\left(\bar{T}_{V}\right)$.

To examine local circulation dynamics, surface wind observations were retrieved from the Mesowest Project (Horel et al. 2002), which compiled available station data from a variety of sources. Data of the Mesowest station winds in Cache Valley are available since 2009. All station records were obtained from the Utah Climate Center [http://beta.climate.usurf.usu.edu/ (under "Climate DataSets")]. Tropospheric data including winds, geopotential height, temperature, and vertical velocity were derived from the National Centers for Environmental Prediction-Department of Energy
Reanalysis II (NCEP2; Kanamitsu et al. 2002) for the period of 1979-2010. Upper-air soundings at the Salt Lake City International Airport (KSLC; location given in Fig. 1) were also used in the geopotential height analysis.

Reconstructing atmospheric conditions over Cache Valley for the period of interest was accomplished through dynamical downscaling using the Advanced Research Weather Research and Forecasting (WRF) model, version 3.1 (Dudhia 2009). Lateral boundary conditions driving the WRF model used the NCEP2 reanalyses. The simulation domain consisted of 1) an outer area $2^{\circ}$ larger than Fig. 1 in each direction with a 12-km resolution and 2) an inner area outlined by the dotted lines in Fig. 1 with a 2-km resolution, using oneway nesting. Simulation periods were conducted from 1 October through 30 April for each winter beginning October 1999. Key model settings include the WRF single-moment three-class simple ice scheme, which suits ice and snow processes for mesoscale grid sizes; the Rapid Radiative Transfer Model for longwave radiation; a downward integration that allows for efficient cloud and clear-sky absorption and scattering for shortwave radiation (Dudhia 1989); the Pleim-Xiu land surface model (Xiu and Pleim 2001); the Asymmetric Convective Model (Pleim 2007) for the planetary boundary layer; and the Betts-Miller-Janjic cumulus parameterization (Betts and Miller 1986; Janjić 1994). To inspect the effect of unphysical waves propagating into the simulation domain as a result of the rapid change in resolution (from $2.5^{\circ}$ to $12 \mathrm{~km}$ ), we have also tested three nested domains of 72,12, and $2 \mathrm{~km}$ for the winter of 2000/01. The result of this triple-nesting simulation (not shown) does not reveal discernible differences from that of the two-nested domain runs.

\section{Results}

\section{a. Local and regional features}

The 10-yr climatology of Cache Valley inversion events, defined as days when the mean daily Logan Peak temperature is greater than the mean daily valley temperature, is depicted in Fig. 2b. Specifically, the average inversion intensity $\left(I_{\text {Inv }}\right.$; orange bars) and inversion frequency $\left(F_{\text {Inv }}\right.$; blue bars) are plotted as a function of days $\left(D_{\text {Inv }}\right)$, where for each day

$$
F_{\text {Inv }} \equiv D_{\text {Inv }} \text { decade }^{-1} \text { and } \quad I_{\text {Inv }} \equiv\left(\overline{T_{P}-T_{V}}\right) / F_{\text {Inv }} .
$$

The peaks of temperature differences and inversion frequency are displaced about a week, although both exhibit a sustained period of high values during mid-January. 
This time displacement indicates the rapid development of inversions and the gradual decline in the inversion intensity, which are common in the valley. The valley inversion climatology is in good agreement with the $\mathrm{PM}_{2.5}$ climatology in terms of seasonal and subseasonal distributions. The correlation coefficient between the mean $\mathrm{PM}_{2.5}$ concentration and the temperature differences (inversion frequency) is $0.61(0.54)$ and is significant at the $95 \%$ confidence interval per $t$ test. This result is in good agreement with the climatological association between $\mathrm{PM}_{2.5}$ concentrations and valley inversions in Cache Valley.

Given the synoptic linkage between prolonged inversions in the IMW valleys and persistent ridging of the upper-level circulations, as indicated earlier (e.g., Wolyn and McKee 1989; Gillies et al. 2010a), we examined the $300-\mathrm{hPa}$ geopotential height retrieved from the 0000 UTC upper-air soundings at the Salt Lake City Airport. As shown in Fig. 2c, the 10-yr climatology of the geopotential height (gray line) exhibits a mid-January peak embedded in the dominant seasonal cycle. The geopotential height averaged over a 32-yr period (19792010) also shows a marked mid-January peak consistent with the 10-yr mean. This peak in geopotential height suggests a "climatological ridge" built up over the IMW during the second and third weeks of January. To illustrate this ridge build-up, the 32-yr mean geopotential height was bandpass filtered with 20-40 days and superimposed on Fig. 2c (red line), based on the 30-day mode that characterizes the winter ridge as suggested in Gillies et al. (2010a,b). The climatological ridge development is clearly embedded in the subseasonal variability, while its phase is consistent with the rises and falls of $\mathrm{PM}_{2.5}$ concentrations and valley inversions during deep winter. These features suggest that the subseasonal variability in Cache Valley's $\mathbf{P M}_{2.5}$ is linked to a similar variation in the large-scale circulations.

To verify such a linkage, Fig. 3a displays the timeheight profile of daily potential temperature lapse rate simulated over Logan (cf. Fig. 1) averaged over the 2001-10 period. Here, the seasonal cycle was removed based on a second-order polynomial fit. An extended period of enhanced stable layer below $650 \mathrm{mb}(\mathrm{hPa})$ appears in mid-January, corresponding to the subseasonal maxima in Fig. 2. Vertical velocity (Fig. 3b) depicts a similar period of persistent downward motion, which supports the stable air in mid-January. The downward motion is sandwiched between ascending motions in early January and early February ascents that are consistent with the drops in $\mathrm{PM}_{2.5}$ concentrations (cf. Fig. 2a). Moreover, both the observed surface wind speed at the Cache Municipal Airport (1 mi northwest of station 1 in Fig. 4a) and the simulated 10-m wind speed averaged

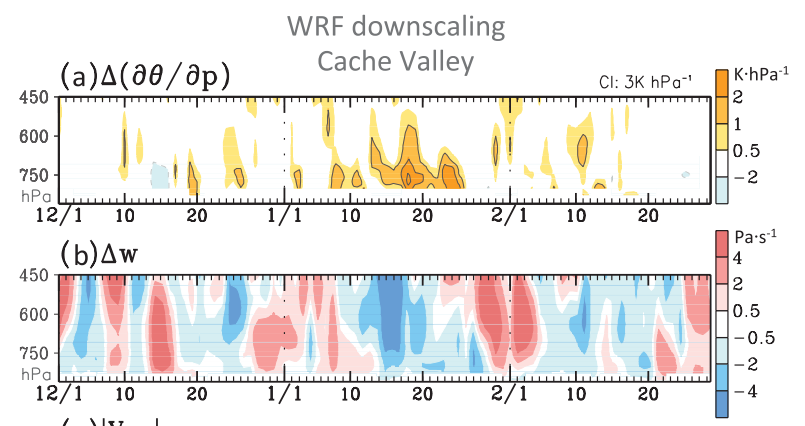

(c) $\left|V_{10 \mathrm{~m}}\right| \quad \Delta$ Cache Airport - WRF simulations

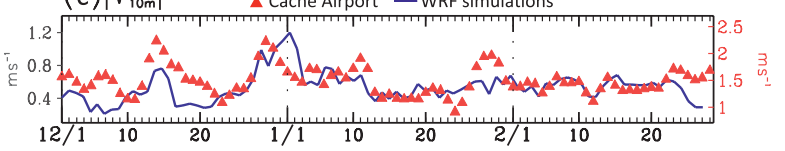

(d) $\nabla \cdot V_{10 m}$ valley floor

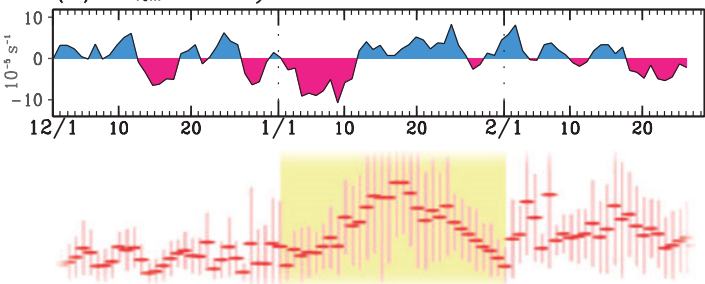

FIG. 3. WRF simulations of the time-height cross sections for daily (a) potential temperature lapse rate, (b) vertical velocity, (c) 10-m wind speeds, and (d) 10-m divergence. The seasonal cycle of each variable was removed (hence the $\Delta$ ). The location for (a) and (b) corresponds to Logan City (cf. Fig. 1a), while the areas of domain average for (c) and (d) include the valley floor with the elevations lower than $1350 \mathrm{~m}$. A stretched version of Fig. 2a is shown at the bottom for easy comparison.

across the valley floor (elevation under $1500 \mathrm{~m}$ ) show decreased wind speeds between 10 and 20 January (Fig. $3 \mathrm{c})$. This supports the aircraft observation by Martin (2006) that prolonged inversion events in Cache Valley are associated with calm winds and enhanced subsidence. Correspondingly, the valley floor divergence-calculated from 10-m winds used in Fig. 3c-depicts a similar period of divergence with the stable layer and sinking air.

The horizontal structure of simulated $10-\mathrm{m}$ winds and $2-\mathrm{m}$ temperature anomalies during the inversion episode of 11-25 January is shown in Fig. 4a, with the seasonal cycle removed. Widespread cooling in Cache Valley accompanies a divergent wind pattern, with apparent outflows near the western exit of the valley (called Cache Junction). This feature echoes the divergent winds observed during high-level $\mathrm{PM}_{2.5}$ episodes in the California Central Valley, in which the divergent surface flows vent through the western valley channel out to the Bay Area (Beaver et al. 2010). Thus, the divergent wind pattern found in Cache Valley is another indication of enhanced subsidence linked to the large-scale ridge development. 
Jan 11-25; seasonal cycle removed

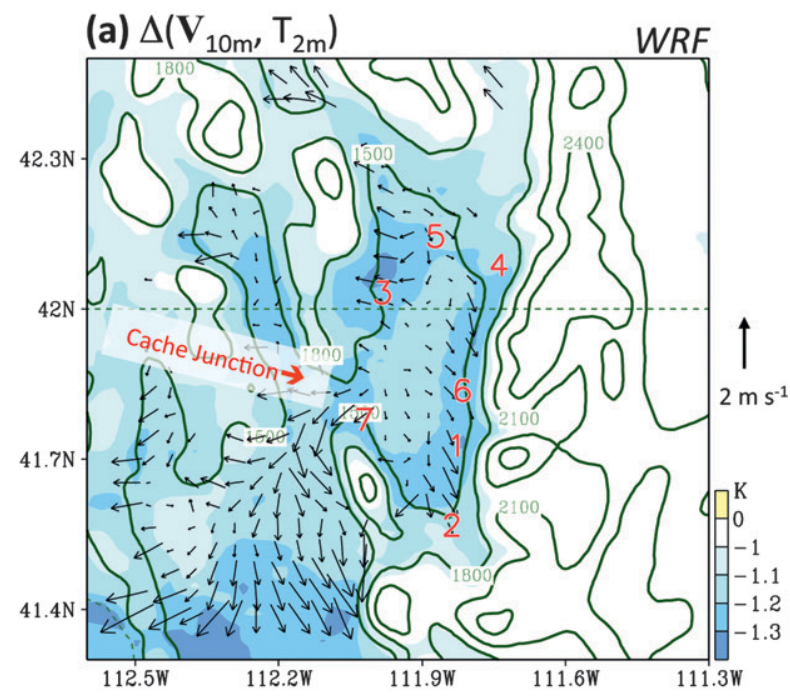

(b) $\Delta(-\partial \theta / \partial p, u, w)$

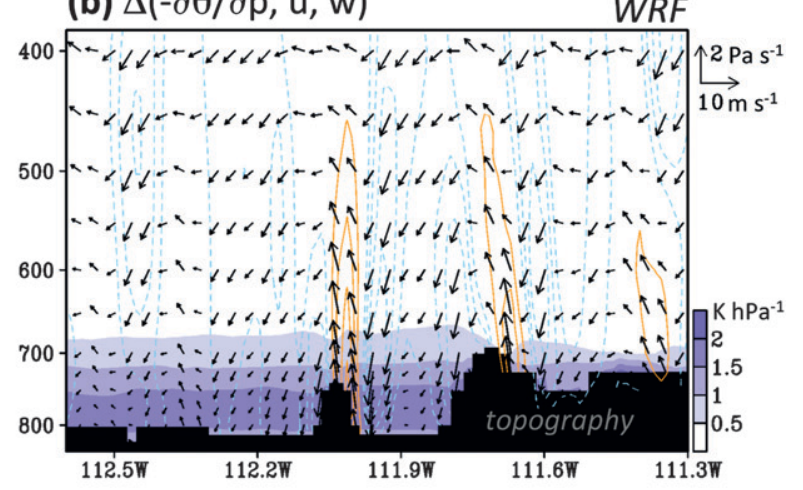

(c) $\Delta \mathbf{V}_{300 \mathrm{mb}}, \Delta \omega_{500-700 \mathrm{mb}}, \Delta \mathrm{T}_{500-700 \mathrm{mb}}$

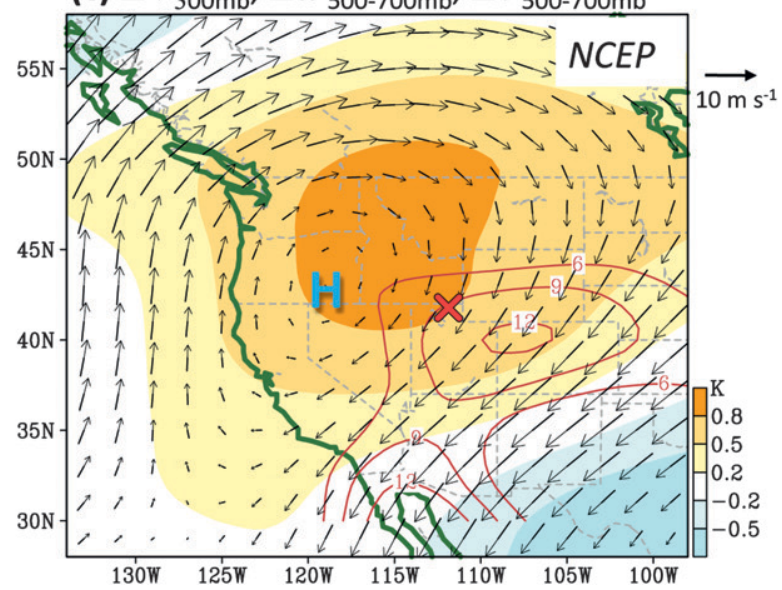

FIG. 4. WRF simulated anomalies of (a) 10-m wind vectors, 2-m temperatures (shadings), and model terrain (contours); (b) sections of east-west circulation vectors, vertical velocity (contours), and potential temperature lapse rate (shadings); and (c) NCEP2 300$\mathrm{mb}$ wind vectors, 500-700-mb mean vertical motion ( $\mathrm{Pa} \mathrm{s}^{-1}$; contours) and temperature (shadings) during 11-25 Jan, with the seasonal cycles removed. In (a), the stations and their identifiers used for computing the surface divergence in Fig. 5a are 1) Logan
For verification purposes, we selected seven Mesowest stations around the rim of the valley floor, as numbered in Fig. 4a with the station names given in the figure caption. Because of data availability we could only examine the 2009/10 winter. Using these stations, one can compute surface divergence of mass flow $D$ through the line integration approach (Chen 1977):

$$
D=\frac{1}{A} \int_{L} v_{n} d l
$$

where $A$ is the enclosed area, $L$ is the circumference of the polygon connecting the seven stations, $v_{n}$ is wind velocity normal to the circumference, and $d l$ is the distance increment along the circumference. The temporal evolution of observed surface divergence from December 2009 through February 2010 is shown in Fig. 5a (red dotted line). The WRF simulation of surface divergence (blue line) is in good agreement with the observed, while the simulated inversion developments (potential temperature lapse rate in Fig. 5b) is verified by the observed temperature differences between Logan Peak and Logan (Fig. 5c). Both the observed and simulated results highlight the association of surface divergence with the inversion event over 7-17 January 2010, as expected, and build confidence in the simulated divergent winds throughout Cache Valley (Fig. 4a).

To further investigate the divergent wind pattern in the climatology, zonal cross sections of vertical circulation and potential temperature lapse rate across Logan during 11-25 January are shown in Fig. 4b. The overall downward velocity and low-level temperature inversions indicate that the mid-January inversion is a regional phenomenon, but not local. Meanwhile, leeside descent is observed over Cache Valley and this may intensify the divergent surface winds in the valley. This process may contribute to the "topographic pocket" effect that traps air pollutants (e.g., Whiteman 2000). At the regional scale (Fig. 4c), the 300-mb wind and 500-700-mb mean vertical velocity and temperature anomalies delineate an anticyclone centered over the Pacific Northwest (derived from the NCEP2 data), with its eastern branch covering much of the IMW. Cache Valley is situated in the overlapping areas of warm air and downward velocity. This supports

AS455, 2) Paradise AT355, 3) Weston CW2247, 4) Preston CW2901, 5) Preston CW4448, 6) Smithfield, and 7) Utah Department of Transportation site SR-30. In (b), contour intervals are $4 \mathrm{~Pa} \mathrm{~s}^{-1}$ for positive and $2 \mathrm{~Pa} \mathrm{~s}^{-1}$ for negative with zeros omitted. In (c), "X" denotes Cache Valley. 


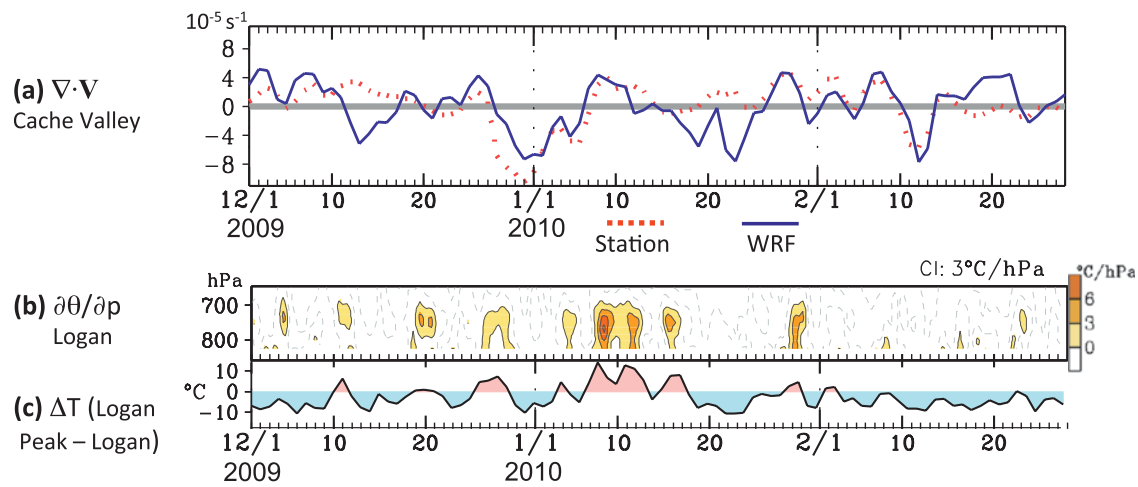

FIG. 5. (a) Surface divergences computed from the seven stations as in Fig. 4a (red dotted line) and the WRF 10-m winds under the 1500-m elevation (blue line), (b) potential temperature lapse rate at Logan, and (c) temperature differences between Logan Peak and Logan from 1 Dec 2009 to 28 Feb 2010. All variables are daily averages.

the simulated inversion conditions in Figs. $4 \mathrm{a}$ and $4 \mathrm{~b}$, linking them to the larger-scale circulation features.

\section{b. Large-scale circulations}

Having connected variations in the local (mesoscale) climatology of Cache Valley to overlying variations in the regional (synoptic-scale) climatology of the U.S. West, we now examine connections of the regional climatology-specifically, the subseasonal ridge buildup - to the overlying hemispheric (planetary-scale) circulation climatology. To understand how large-scale flows vary on subseasonal time scales, or to investigate whether subseasonalities exist at all, we employed an empirical orthogonal function (EOF) analysis as an independent measure (i.e., not a regression product of a local sounding). However, it is important to first filter out the dominant seasonal cycle, leaving any subseasonal components to be compared with local sounding analyses. As our measure of planetary circulation, we used the NCEP2 300-mb geopotential height field and associated derivatives.

Informed by our synoptic and mesoscale results, we bandpass filtered the daily $300-\mathrm{mb}$ geopotential height (1979-2010 mean) at 20-40 days and subjected the filtered signal to the EOF analysis for the October-March period. The leading EOFs, determined by the variance exceeding $10 \%$, are shown in Figs. $6 \mathrm{a}$ and $6 \mathrm{~b}$ (shadings). To facilitate the comparison of these EOFs with the mean seasonal circulation, we plotted the DecemberFebruary (DJF) mean geopotential height with the zonal average removed. This leaves "eddies" in the stationary waves and highlights the trough/ridge pattern (contours). The first EOF depicts a wave train pattern across the North Pacific rim. As compared with the winter mean eddy geopotential height, the first EOF appears to be phased "in quadrature" with the winter standing waves (e.g., Lau 1979). The second EOF depicts a similar wave train, which is weaker in the variance and whose phase is shifted westward by about $15^{\circ}$.

To depict the temporal relationship between the first and second EOFs, we adopted the "EOF dial" approach commonly used in the MJO studies (e.g., Wheeler and Hendon 2004) - that is, plotting the two leading EOF coefficients [or principal components (PCs)] in a scatter diagram to detect the oscillation's life cycle. The resulting scatters reveal phase relationship between PC1 and $\mathrm{PC} 2$ in the sense that when one reaches its maximum phase, the other will be at minimum phase if they evolve in an oscillatory manner. This "phase diagram" diagnostic has been applied in MJO prediction (see, e.g., http://www.cpc.ncep.noaa.gov/products/precip/CWlink/ $\mathrm{MJO} /$ foregfs.shtml). Figure $6 \mathrm{c}$ illustrates the phase diagram of the leading PCs corresponding to the EOFs in Figs. $6 \mathrm{a}$ and $6 \mathrm{~b}$. Two round dials appear during early December through late February. In other months, the amplitude is considerably weak and the phase is random. This character suggests that the two EOFs evolve back and forth in an oscillatory manner-and this happens at the subseasonal time scale. For example, $\mathrm{PC1}$ reaches its maximum in the first half January while PC2 is at its minimum, so the circulation is changing toward that revealed in EOF1, which shows an anticyclone over Utah. In the second half of January, PC1 becomes minimum while PC2 reaches maximum, suggesting that the anticyclone is retreating from Utah.

Such an evolution is further substantiated in the longitude-time cross section of the daily mean 300-mb geopotential height across $45^{\circ} \mathrm{N}$ over western North America (Fig. 6d). The winter mean ridge appears to undergo a subseasonal shift in the zonal direction around January. The illustration is enhanced by the smoothed 10-day running average of geopotential height (thick 

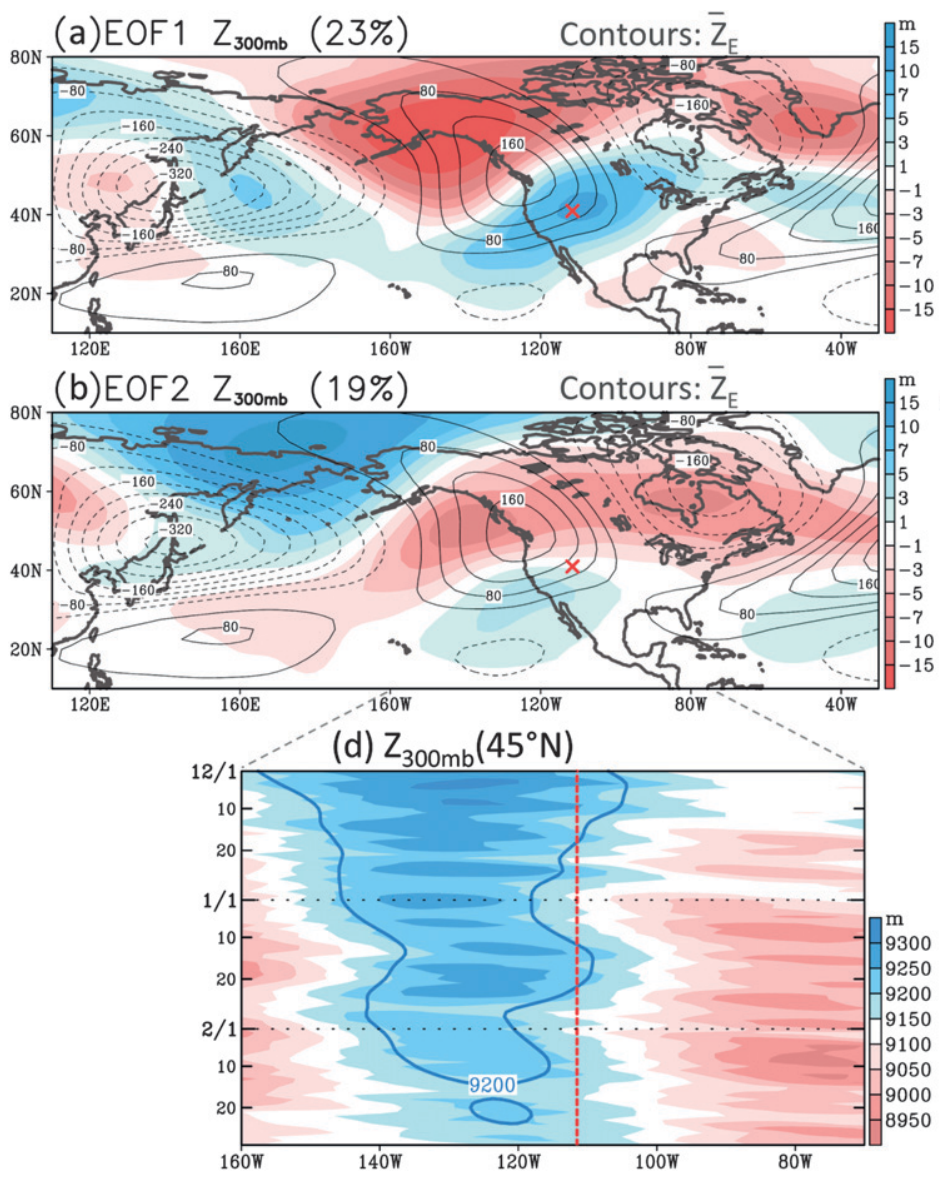

(c)PC1 vs. PC2

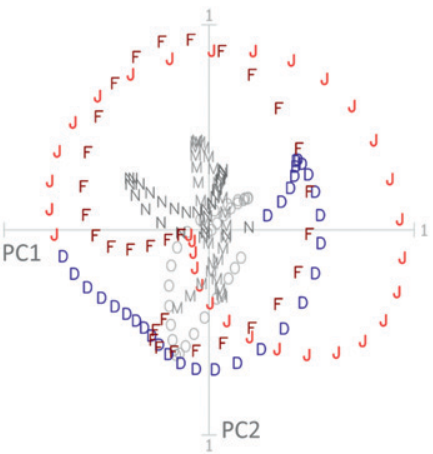

FIG. 6. (a),(b) Leading EOFs (shadings) of the bandpass filtered geopotential height at $300 \mathrm{mb}$ with $20-40$ days, superimposed with the climatological mean eddies (contours). Cache Valley is indicated by the red X. (c) Scatterplot for the normalized PCs from October through March with different colors for December, January, and February. (d) Longitude-time evolution of the $300-\mathrm{mb}$ geopotential height across $45^{\circ} \mathrm{N}$ overlaid with the $9200-\mathrm{m}$ isobar from the 10-day running average.

contours) depicting the eastward intrusion starting 10 January and the westward retreat beginning 20 January, with a subsequent eastward shift around 10 February. Such a zonal movement of the winter ridge is distinct from the seasonal tropospheric variations that are dominated by a zonally stratified, north-south migration of momentum and mass across the midlatitudes (e.g., Thompson and Wallace 2000). This east-west shift in the winter ridge is consistent with the timing of, and provides a mechanism for, the mid-January maxima of temperature inversions and $\mathrm{PM}_{2.5}$ concentrations in Cache Valley.

Finally, it is worth exploring how such variability might arise in the climatological mean of the largescale circulations. Possible dynamics of the subseasonal variability were examined by identifying the forcing source for stationary wave anomalies (the so-called Rossby wave source; Hoskins and Ambrizzi 1993) through the wave-activity flux. Focusing on the phaseindependent wave-activity flux for stationary and migratory waves, Takaya and Nakamura (2001) derived the wave-activity flux $\mathbf{W}$ as

$$
\mathbf{W}=\frac{1}{2|\mathbf{U}|}\left[\begin{array}{l}
u\left(\psi_{x}^{2}-\psi \psi_{x x}\right)+v\left(\psi_{x} \psi_{y}-\psi \psi_{x y}\right) \\
u\left(\psi_{x} \psi_{y}-\psi \psi_{x y}\right)+v\left(\psi_{y}^{2}-\psi \psi_{y y}\right)
\end{array}\right],
$$

where $\psi$ is the perturbation streamfunction, the subscripts represent partial derivatives, and $\mathbf{U}$ is the twodimensional DJF mean flow of $(u, v)$. Equation (2) is an extension of the Eliassen-Palm relation (Plumb 1985) defined on the logarithmic pressure coordinate system for the zonally averaged basic state. In general, the wave-activity flux vector is parallel to the group velocity of Rossby waves, while convergence of the waveactivity flux indicates amplification of the wave energy 

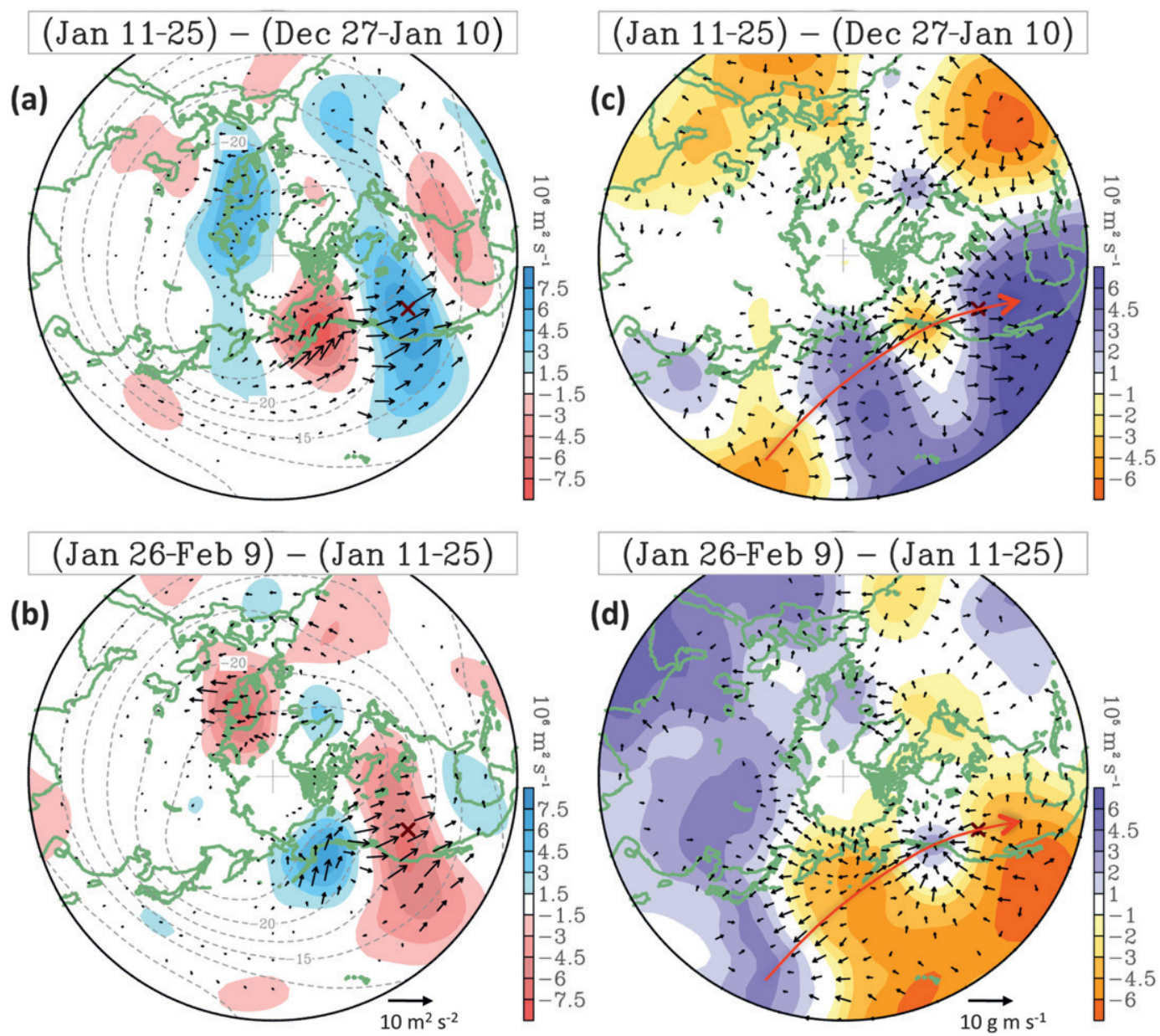

FIG. 7. (a),(b) Differences in the 300-mb streamfunction (shadings) and the associated wave activity flux (vectors), superimposed with the DJF mean streamfunction (gray dashed contours; interval $10^{7} \mathrm{~m}^{2} \mathrm{~s}-1$ ), between the periods as indicated. (c),(d) The corresponding velocity potential (shadings) and divergent wind vectors. Red arrows in (c) and (d) outline the possible wave train emanating from the tropical western Pacific.

and enstrophy. The calculation of Eq. (2) is independent of any spatial or time averaging, making it ideal for analyzing wave activity at any particular time.

Figure 7a shows the wave-activity flux (vectors) associated with the $300-\mathrm{mb}$ streamfunction differences (shadings) between 11-25 January and 27 December10 January, when the anticyclonic anomaly begins developing over the IMW (cf. Fig. 6d). The winter mean streamfunction is overlaid as contours to portray the background flows. The development of the anticyclone over the IMW coincides with strong wave-activity flux across the upstream region and with convergence to the southeast of the anticyclone, suggesting that the inflow of wave energy originates from the central-western North Pacific Ocean, where divergence of wave-activity flux is prevalent. Organized streamfunction anomalies associated with weak wave-activity flux are also present over the tropical western Pacific, albeit weaker. This indicates a possible Rossby wave source in the subtropics, as was proposed by previous studies (e.g., DeWeaver and Nigam 2004; Jiang and Lau 2008). For the cyclonic anomaly over the IMW (Fig. 6b; between 26 January-9 February and 11-25 January), the streamfunction and wave-activity flux are similarly apparent in western North America and northeast Pacific but are weak over the western Pacific.

Also noteworthy is the seesaw pattern of streamfunction between the northeast Atlantic and Scandinavia and associated eastward directing wave-activity flux. This observation echoes the seesaw between low-frequency variabilities of the Aleutian low and the Icelandic low (e.g., Blackmon et al. 1977, 1984), a known climatological feature of the circumpolar circulations associated with the seasonal cycle (Swanson 2007; Nakamura et al. 2010). In addition, tropical linkage with this subseasonal variation is plausible. This is revealed by the wavelike pattern 
(a) Precip DJF mean

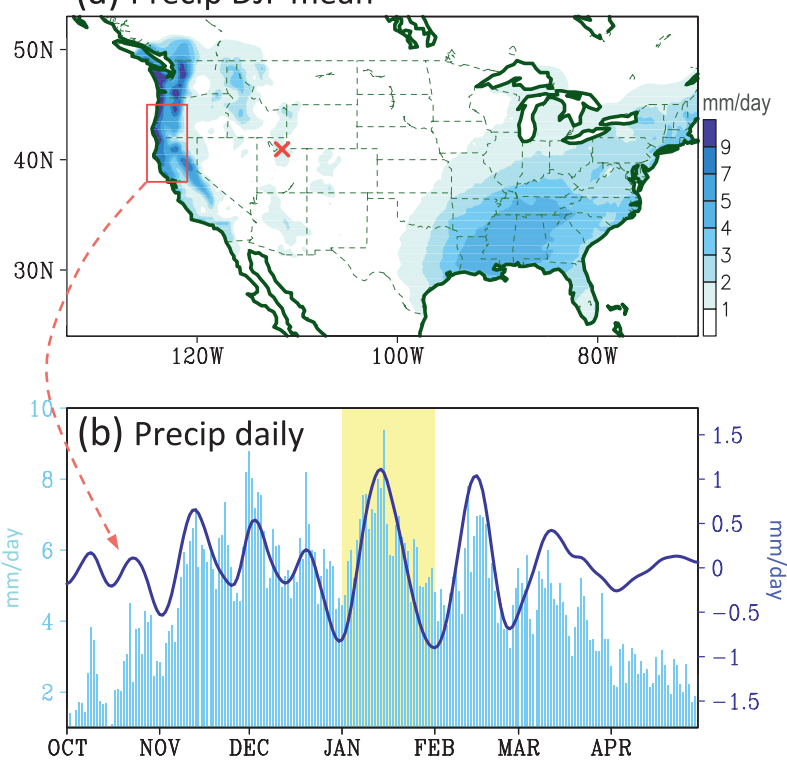

FIG. 8. (a) Winter (DJF) mean precipitation over the United States and (b) daily evolution of coastal precipitation in Oregon and northern California [i.e., boxed region in (a)], overlaid with band-passed precipitation following the filtering in Fig. 2c. The $X$ in (a) indicates Cache Valley; the yellow strip in (b) indicates January.

of the velocity potential anomalies emanating from the tropical western Pacific (Figs. 7c,d) and coupled with the streamfunction wave train. The phases of these wave trains are in quadrature between velocity potential and streamfunction, with upper-level divergence (convergence) coupled to positive (negative) cyclonic vorticity advection (i.e., to the east of streamfunction). This feature suggests that the wave train is dynamically maintained, since vorticity advection (i.e., in quadrature with the streamfunction wave train) is somewhat balanced by vortex stretching (i.e., induced from the velocity potential wave train).

What is less clear is why such subseasonal variability has a climatological footprint and a preferred timeframe. It has been noted that the tropical intraseasonal variability (TISV) has a tendency to be seasonally "locked," meaning that certain modes of TISV exhibit similar phases over similar time periods (Lau 2005). For instance, the quasi-stationary mode of TISV is particularly active in January during El Niño years (cf. Fig. 9.14 of Lau 2005). Because this quasi-stationary mode of TISV induces the teleconnection toward North America, similar to the process as depicted in Fig. 7, it is likely to play a part in the formation of the climatological wave trains. Further analysis is required to explore such a linkage.

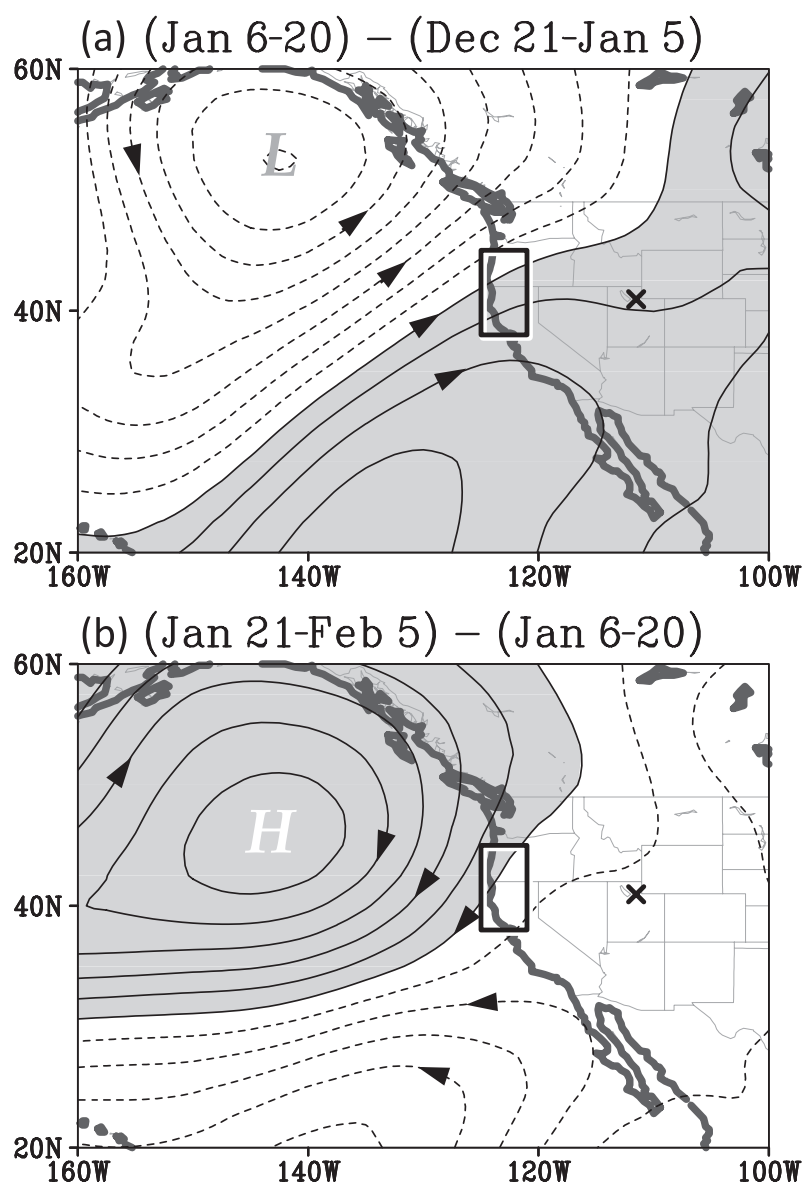

FIG. 9. As in Figs. 7a and 7b, but for the $850-\mathrm{mb}$ streamfunction during the periods indicated at the top. The contour interval is $5 \times$ $10^{6} \mathrm{~m}^{2} \mathrm{~s}^{-1}$ while positive values are shaded in gray. The boxed area follows that in Fig. 8a for precipitation.

\section{c. Other local impact}

Given the broad spatial scale of the subseasonal circulation change, it is reasonable to suspect that the climate in other part of the western United States is affected. For this reason we inspected the climatological daily precipitation along the West Coast, averaged in Oregon and northern California where large winter precipitation occurs (Fig. 8a; boxed area). Time series of the daily precipitation over that area reveal noticeable subseasonal variability during the cold season (November-March; Fig. 8b). The bandpass filtered precipitation (solid line) further depicts two substantial "cycles" during January-February, corresponding to the timing of the mid-January subseasonal peak of $\mathrm{PM}_{2.5}$ in Cache Valley (cf. Fig. 2a). A closer examination and a cross correlation (not shown) found that the January precipitation peak in Oregon and northern Oregon occurs about 5 days prior to the peak 
in Cache Valley $\mathrm{PM}_{2.5}$. We further examined the change in synoptic flows, as is shown by the differences in the 850-mb streamfunction between 6-20 January and 21 December-5 January (Fig. 9a) and between 21 January-5 February and 6-20 January (Fig. 9b) (i.e., shifted 5 days earlier compared to Fig. 7). A cyclonic anomaly forms in the Gulf of Alaska, supplying lowlevel southwesterly flows (i.e., warm and moist) to the northwest coasts during the time when the precipitation there increases. About 15 days later, the circulation anomaly is replaced by an anticyclone that forms northeasterly flows (i.e., cool and dry) out over the northwest coasts when the precipitation decreases. The results presented here and in section $3 \mathrm{~b}$ therefore suggest that the subseasonal oscillation in the winter mean ridge affects local climate not only in the interior west but also (as a result of precipitation) along the West Coast.

\section{Concluding remarks}

A subseasonal signal in the local climatology of Cache Valley has led us to disclose a subseasonal variation in the overlying large-scale circulations. The observation that the mid-January peak in $\mathrm{PM}_{2.5}$ is closely linked with valley inversions is not surprising; however, the evidence that these inversions are driven by subseasonal variations in the large-scale circulation is an interesting result. Specifically, climatological analysis of the western U.S. winter mean ridge reveals a mid-January subseasonal shift in the zonal direction-an eastward displacement-likely in response to variations in the Rossby wave source over the central North Pacific (though more distant wave sources in the tropical Pacific are also possible in the teleconnection). This displacement of the winter mean ridge, in turn, impacts regional-scale atmospheric conditions-specifically, subsidence with local leeside enhancements and midlevel warming over Cache Valley-as derived from dynamical downscaling (WRF model).

The analyses of this study indicate that the subseasonal peak of the long-term mean $\mathrm{PM}_{2.5}$ concentrations in Cache Valley is neither a coincidence nor a result of statistical manipulation. Instead, evidence suggests that such variability is linked to the large-scale circulations' subseasonal evolution, which involves complex dynamics and remote forcing in the circumpolar circulations, as well as possible tropics-midlatitude interactions. Further understanding of the physical mechanism in forming the subseasonal variability of the climatological mean circulations may improve long-range forecasting (i.e., beyond 10 days) of both valley inversions and high-concentration air pollutant episodes throughout the IMW and other geographically similar regions. For instance, climate models that can capture the climatological subseasonality in the winter mean circulations will likely perform better than models that cannot. Situations like this are worth investigating.

Acknowledgments. Station data compilation by Jonathan Carlisle is highly appreciated. We are grateful to Hisashi Nakamura for sharing the wave-activity flux program code. We also thank two anonymous reviewers for their insightful comments. This study was partially supported by the Utah Agricultural Experiment Station, Utah State University, as journal paper number 8292.

\section{REFERENCES}

Beaver, S., and Coauthors, 2010: Pattern-based evaluation of coupled meteorological and air quality models. J. Appl. Meteor. Climatol., 49, 2077-2091.

Betts, A. K., and M. J. Miller, 1986: A new convective adjustment scheme. Part II: Single column tests using GATE wave, BOMEX, ATEX and arctic air-mass data sets. Quart. J. Roy. Meteor. Soc., 112, 693-709.

Blackmon, M. L., J. M. Wallace, N.-C. Lau, and S. L. Mullen, 1977: An observational study of the Northern Hemisphere wintertime circulation. J. Atmos. Sci., 34, 1040-1053.

_ , Y.-H. Lee, J. M. Wallace, and H.-H. Hsu, 1984: Time variation of 500-mb height fluctuations with long, intermediate and short time scales as deduced from lag-correlation statistics. J. Atmos. Sci., 41, 981-991.

Chen, W. Y., 1977: Analysis of vorticity and divergence fields and other meteorological parameters over Lake Ontario during IFYGL. Mon. Wea. Rev., 105, 1298-1309.

DeWeaver, E., and S. Nigam, 2004: On the forcing of ENSO teleconnections by anomalous heating and cooling. J. Climate, 17, 3225-3235.

Dudhia, J., 1989: Numerical study of convection observed during the Winter Monsoon Experiment using a mesoscale twodimensional model. J. Atmos. Sci., 46, 3077-3107.

— 2009: WRF version 3.1: New features and updates. Proc. 10th Annual WRF Users' Workshop, Boulder, CO, NCAR. [Available online at http://www.mmm.ucar.edu/wrf/users/ workshops/WS2009/presentations/1-01.pdf.]

Gillies, R. R., S.-Y. Wang, and M. R. Booth, 2010a: Atmospheric scale interactions on wintertime Intermountain West low-level inversions. Wea. Forecasting, 25, 1196-1210.

, — - J.-H. Yoon, and S. Weaver, 2010b: CFS prediction of winter persistent inversions in the Intermountain Region. Wea. Forecasting, 25, 1211-1218.

Higgins, R. W., J.-K. E. Schemm, W. Shi, and A. Leetmaa, 2000: Extreme precipitation events in the western United States related to tropical forcing. J. Climate, 13, 793-820.

Horel, J., and Coauthors, 2002: MesoWest: Cooperative mesonets in the western United States. Bull. Amer. Meteor. Soc., 83, 211-225.

Hoskins, B. J., and T. Ambrizzi, 1993: Rossby wave propagation on a realistic longitudinally varying flow. J. Atmos. Sci., 50, 16611671.

Janjić, Z. I., 1994: The step-mountain eta coordinate model: Further developments of the convection, viscous sublayer, and turbulence closure schemes. Mon. Wea. Rev., 122, 927-945. 
Jiang, X., and N.-C. Lau, 2008: Intraseasonal teleconnection between North American and western North Pacific monsoons with 20-day time scale. J. Climate, 21, 2664-2679.

Kanamitsu, M., W. Ebisuzaki, J. Woollen, S.-K. Yang, J. J. Hnilo, M. Fiorino, and G. L. Potter, 2002: NCEP-DOE AMIP-II reanalysis (R-2). Bull. Amer. Meteor. Soc., 83, 1631-1643.

Lau, N.-C., 1979: The observed structure of tropospheric stationary waves and the local balances of vorticity and heat. J. Atmos. Sci., 36, 996-1016.

— westward-propagating, planetary-scale fluctuations with approximately three-week periods. Mon. Wea. Rev., 127, 2324-2345.

Lau, W. K.-M., 2005: El Niño-Southern Oscillation connection. Intraseasonal Variability in the Atmosphere-Ocean Climate System, W. K.-M. Lau and D. E. Waliser, Eds., Praxis Publishing, 271-300.

Malek, E., T. Davis, R. S. Martin, and P. J. Silva, 2006: Meteorological and environmental aspects of one of the worst nationa air pollution episodes (January, 2004) in Logan, Cache Valley, Utah, USA. Atmos. Res., 79, 108-122.

Martin, R. S., 2006: Cache Valley air quality studies. Utah Department of Environmental Quality Tech. Rep., 91 pp. [Available online at http://www.airquality.utah.gov/Public-Interest/CurrentIssues/cache-valley-PM/Outreach/Cache \%20Valley\%20Air\% 20Quality\%20Studies\%202006.pdf.]

Mo, K. C., 1999: Alternating wet and dry episodes over California and intraseasonal oscillations. Mon. Wea. Rev., 127, 2759-2776.

Nakamura, H., T. Miyasaka, Y. Kosaka, K. Takaya, and M. Honda, 2010: Northern Hemisphere extratropical tropospheric planetary waves and their low-frequency variability: Their vertical structure and interaction with transient eddies and surface thermal contrasts. Climate Dynamics: Why Does Climate Vary? Geophys. Monogr., Vol. 189, Amer. Geophys. Union, 149-179.
Pleim, J. E., 2007: A combined local and nonlocal closure model for the atmospheric boundary layer. Part I: Model description and testing. J. Appl. Meteor. Climatol., 46, 1383-1395.

Plumb, R. A., 1985: On the three-dimensional propagation of stationary waves. J. Atmos. Sci., 42, 217-229.

Reeves, H. D., and D. J. Stensrud, 2009: Synoptic-scale flow and valley cold pool evolution in the western United States. Wea. Forecasting, 24, 1625-1643.

Silva, P. J., E. L. Vawdrey, M. Corbett, and M. Erupe, 2007: Fine particle concentrations and composition during wintertime inversions in Logan, Utah, USA. Atmos. Environ., 41, 54105422.

Swanson, K. L., 2007: Storm track dynamics. The Global Circulation of the Atmosphere, T. Schneider and A. H. Sobel, Eds., Princeton University Press, 78-103.

Takaya, K., and H. Nakamura, 2001: A formulation of a phaseindependent wave-activity flux for stationary and migratory quasigeostrophic eddies on a zonally varying basic flow. J. Atmos. Sci., 58, 608-627.

Thompson, D. W. J., and J. M. Wallace, 2000: Annular modes in the extratropical circulation. Part I: Month-to-month variability. J. Climate, 13, 1000-1016.

Wheeler, M. C., and H. H. Hendon, 2004: An all-season real-time multivariate MJO index: Development of an index for monitoring and prediction. Mon. Wea. Rev., 132, 1917-1932.

Whiteman, C. D., 2000: Mountain Meteorology: Fundamentals and Applications. Oxford University Press, $355 \mathrm{pp}$.

Wolyn, P. G., and T. B. McKee, 1989: Deep stable layers in the intermountain western United States. Mon. Wea. Rev., 117, 461-472.

Xiu, A., and J. E. Pleim, 2001: Development of a land surface model. Part I: Application in a mesoscale meteorological model. J. Appl. Meteor., 40, 192-209. 